\title{
DA ANÁLISE TÉCNICA À LEITURA LITERÁRIA: ABORDAGENS DA LITERATURA NA ESCOLA
}

\author{
FROM TECHNICAL ANALYSIS TO LITERARY READING: \\ APPROACHES TO LITERATURE AT SCHOOL
}

Neide REZENDE ${ }^{1}$

\begin{abstract}
Resumo: O presente artigo busca comparar duas concepções e métodos diferentes de ensino de literatura presentes nas últimas quatro décadas no Brasil - uma centrada no uso de terminologia técnica para abordar o texto, e outra com foco no leitor. Busca-se, também, apreender aspectos do contexto escolar que promoveram tais mudanças no âmbito da didática da literatura nesse tempo. Essas comparações partem de situações colhidas mediante experiência docente no ensino médio, ambas as práticas centradas na abordagem do romance $A$ hora da estrela, de Clarice Lispector. A primeira situação, colhida em fins da década de 1980, quando esta autora era professora no ensino médio e reproduzia uma abordagem recorrente entre os docentes e presente nos livros didáticos; a segunda situação foi colhida no artigo assinado por esta autora e por sua doutoranda (SOARES, REZENDE, 2019), a partir do relato de atividades desta última sobre a novela de Clarice Lispector abordada no ensino médio de um instituto federal, cerca de duas décadas depois da primeira situação. A análise de ambas busca mostrar uma consequente mudança de perspectiva didática que, paulatinamente, tem sido objeto de pesquisas acadêmicas e de algumas práticas escolares, alavancadas por teorias como as da Estética da Recepção (JAUSS, 1994) e da Leitura Literária (ROUXEL, 2013).
\end{abstract}

Palavras-chave: Leitura literária. Estética da recepção. Ensino de literatura. A hora da estrela. Clarice Lispector.

Abstract: This paper seeks to compare two different conceptions and methods of teaching literature which has been present in the last four decades in Brazil - one centered in the use of technical terminology to approach the text and the other focused on the reader. It also seeks to apprehend aspects of the school context that promoted such changes in the scope of literature didactics. The comparison is based on two high school experience of exploring the novel A hora da Estrela, by Clarice Lispector. The first situation was taken in the late 1980s, when I was a high school teacher who reproduced the recurrent approach among teachers; and the second situation was taken from Soares \& Rezende (2019), based on the latter author's activities about two decades after the first situation. The analysis of both situations evinces the change in didactic perspective, which has gradually been the subject of academic research and some school practices that are leveraged by theories such as the Aesthetics of Reception (JAUSS, 1994) and Literary Reading (ROUXEL, 2013).

Keywords: Literary reading. Reception aesthetics. Literature teaching. Clarice Lispector.

\section{Temporalidades distintas na abordagem de $\boldsymbol{A}$ hora da estrela} - "Professora, Macabéa é plana ou redonda?" (Pergunta de duas alunas de Ensino Médio abordando
esta professora no corredor da escola em fins da década de 1980).

\footnotetext{
${ }^{1}$ Professora da Faculdade de Educação da Universidade de São Paulo (USP). Doutorado em Educação pela USP. E-mail: neirez@usp.br.
} 
- "O desfecho da história foi triste para muitos deles, como um grupo que veio até mim na sala dos professores para lamentar a morte de Macabéa". (Relato de professora do Ensino Médio após a leitura de $A$ hora da estrela) (SOARES, REZENDE, 2019).

A esses diferentes eventos sobre o romance de Clarice Lispector correspondem, decerto, concepções diferentes do trabalho com a literatura na escola, que tanto podem se articular como se excluir.

A preocupação em definir o tipo da personagem, no primeiro caso, a partir de uma categoria técnica - de resto, inadequada para a obra, como comentaremos adiante -, vincula-se a uma perspectiva que todos nós, professores de língua portuguesa, conhecemos de sobra e que, com muita probabilidade, já foi amplamente mobilizada pelos mais velhos. De fato, algumas configurações de conteúdo e de abordagens se instalaram de tal modo nas disciplinas escolares que, mesmo depois de criticadas pelos especialistas da área, quando novos ângulos do objeto ficam visíveis e fazem com que percam consistência ou prestígio, ainda permanecerão ativas residual ou integralmente durante muitas gerações de docentes.

Essa perspectiva de análise provinda do linguista e historiador André Chervel (1990), em artigo muito conhecido na área de Educação - "História das disciplinas escolares: reflexões sobre um campo de pesquisa" -, mostra como determinados conteúdos e suas formas de apropriação aderem de tal maneira às disciplinas que parecem pertencer à sua natureza, sendo utilizados como se fossem próprios delas, configurando aquilo que, na área de história da educação, se delineou como "cultura escolar", hoje um importante campo de investigação. Chervel traz como exemplo o ensino da gramática na disciplina do Francês, língua materna, que, segundo ele, corresponde a uma articulação de interesses entre o social - onde há a convicção de que falar bem se aprende com as regras gramaticais normativas - e o escolar; entre nós, além de partilhar essa crença no ensino de gramática, podemos incluir também a História da Literatura na disciplina de Língua Portuguesa - ou seja, ensina-se História da Literatura para formar leitores e ensinar Literatura.

Embora ainda faltem pesquisas mais detidas sobre a permanência no Ensino Médio e o valor que a História da Literatura tem para os professores, há alguns estudos hoje sobre essa etapa da aprendizagem que de algum modo abordam o tema e podem sustentar nossa reflexão sobre a questão da abordagem técnica de narrativas. Destaco, dentre esses, a pesquisa de Gabriela Rodella de Oliveira (2013) junto aos professores de Português sobre o ensino de literatura e suas relações entre formação, hábitos de leitura e práticas de ensino na rede pública estadual de São Paulo. A autora, que coletou dados mediante questionários e entrevistas, conclui que as atividades do professor com a história da literatura - exposição sobre a vida do autor, o 
contexto e o estilo da época em que viveu, além da leitura de fragmentos das obras, solicitações aos alunos de estudos do modo de pensar da época, características da época etc. - "parecem indicar um trabalho que prescinde da leitura do texto literário e da análise de suas peculiaridades formais, concentrando-se, ao contrário, no entorno da obra" (OLIVEIRA, 2013, p. 128). Aliada a esse ensino, aparece, segundo a autora, a preocupação com os livros dos exames vestibulares. Sendo esta uma coleta de dados realizada em 2007-8 (decorrente de pesquisa de mestrado na Faculdade de Educação da USP), é de se imaginar que o cenário descrito seja bastante semelhante ao que se fazia nas décadas anteriores, quando eu mesma era professora de ensino médio e registrei a questão das duas alunas aqui exposta, o que me permite, então, algumas considerações críticas a respeito.

Sugeríamos naqueles tempos idos, obviamente, que as leituras fossem feitas pelos estudantes, mas estas não eram objeto do trabalho em classe, tampouco se acreditava que a interpretação dos alunos pudesse ser legítima. Não importava, no fundo, se as obras fossem lidas ou não, pois não se tratava da leitura individual, mas da apreensão da obra mediante aparatos técnicos de um certo tipo de análise - o que, evidentemente, não interessava aos alunos. É disso que se lamenta Todorov (2009) no livro Literatura em perigo, ao comentar como a teoria literária substituía a leitura das obras e se apresentava como conteúdo exclusivo da matéria, como se fosse o todo desse ensino, e não um dos aportes possíveis capazes de descortinar ângulos da realidade à qual pertencem os objetos dessas disciplinas, incapazes, por si só, de construírem sentidos para bem formar o usuário da língua e o leitor de literatura.

Esses são assuntos meio que perenes e preocupações dos estudantes da Licenciatura em Letras - "ensinar ou não gramática", "como lidar com a historicidade das obras sem se fundamentar nos períodos literários" - que ainda hoje perpassam as aulas. E o curioso é que os estudantes, no curso superior (pelo menos das universidades públicas) estão em contato (nas disciplinas) e/ou participando de pesquisas (mediante diversos programas da graduação) que buscam atualizar as teorias. Porém, quando eles pensam em conteúdos e didáticas no ensino básico, fixam-se no que conheceram quando lá estudaram, confirmando a tese de Chervel de que certos conteúdos e métodos - a gramática e exercícios de identificação e classificação de orações; a história da literatura, com sua linha do tempo; e exercícios com trechos de obras para identificar seus estilos de época - perenizam na "cultura escolar". Cabe aos cursos de Licenciatura mudarem essas representações. 


\section{A análise do texto literário pela terminologia técnica}

Prosseguindo com o primeiro exemplo, sobre se Macabéa era plana ou redonda, a tentativa de identificação do tipo de personagem respondia, naquelas décadas finais do século XX, a um ensino pautado em uso estereotipado de certa teoria da literatura, em parte veiculada pelos livros didáticos ${ }^{2}$, em parte reminiscência daquela cultura escolar centrada em questões sobre o texto, cuja terminologia podia ser recuperada do livro Aspectos do romance, de 1927, de Edward M. Forster (1879-1970), romancista e crítico inglês da primeira metade do século $\mathrm{XX}$.

A abordagem nas aulas era feita a partir dos fragmentos de obras dos períodos literários lidos em sala e da suposta leitura feita pelos alunos, checada mediante exercícios de compreensão e explicação do texto no livro didático ou nos chamados paradidáticos. Centrados no texto, esses instrumentos de análise decerto eram úteis para os críticos, mas, autonomizados - fora do contexto teórico de origem, deslizados para o trabalho escolar de ensino básico e para a obra de Clarice Lispector -, decididamente, não funcionavam. Primeiro, porque, como dissemos, essa terminologia técnica - à qual se juntam o espaço, se exterior ou interior; o tempo, se cronológico ou psicológico; o narrador, se onisciente ou não etc. - vinha conceitualmente desvestida de suas potencialidades de interpretação, posto que reduzidas à identificação e classificação; segundo, porque o romance de Clarice não é definido por um enredo mimético; ele tematiza sua própria composição, problematizando justamente aquilo que poderia ser a caracterização de uma possível personagem, de uma ação ou de um narrador "realista"3. Sem esse trabalho de discussão sobre a modernidade da narrativa, seria difícil caracterizar a personagem, se plana ou redonda, já que, para isso, era preciso verificar se haveria dimensão humana, uma profundidade psicológica nesse caráter da personagem, ou se essa dimensão não existia e se a personagem era previamente fixada (o tipo), o que, de fato, não se aplica no caso de Macabéa, cujo narrador-autor oferece ao leitor a coparticipação na construção da personagem, não estando a narrativa marcada pelo caráter e ação da personagem, mas pelos percalços ao produzi-la. Ainda assim, o instrumental analítico mobilizado até poderia servir se,

\footnotetext{
${ }^{2}$ Chamo a atenção para a pesquisa de mestrado de Carolina Yokota de Oliveira, Um estudo sobre a concepção de literatura presente no discurso dos manuais didáticos (entre os anos de 1970 a 1990), defendida na Faculdade de Educação da Universidade de São Paulo, em 2008, sob minha orientação. De base teórica foucaultiana, a análise de Carolina Yokota conclui que o livro didático apresenta certos discursos que se afirmaram como "verdades" e funcionam como chaves de interpretação, dispensando uma investigação mais apurada do objeto de análise, uma vez que ideias e noções já se encontram previamente determinadas e fixadas.

${ }^{3} \mathrm{O}$ próprio Forster reconhece que as personagens “Tentam viver suas próprias vidas e, com frequência, atraiçoam o esquema fundamental do livro. 'Fogem', escapam do nosso controle': são criações dentro de uma criação e, em relação a esta, muitas vezes desarmoniosas. Se lhes é dada completa liberdade, fazem o livro em pedaços; caso mantidas sob controle muito rigoroso, vingam-se morrendo, e destroem-no por decomposição interna" (FORSTER, 1998, p. 64). Não é essa dificuldade tematizada como enredo de A hora da estrela?
} 
de fato, funcionalizado de modo crítico e a contrapelo, considerando que esse texto, justamente, ergue uma barreira distanciada e irônica frente ao gênero, originando até um desconforto no leitor crítico ao caracterizá-lo como "romance".

Assim, se a intenção era revelar a qualidade artística do texto literário de Clarice Lispector, essa abordagem não funcionava, seja porque não correspondia à forma de composição da obra - ou seja a explicação sobre sua execução não produzia um tipo de conhecimento capaz de causar alguma espécie de satisfação, caso fosse um leitor mais maduro -, tampouco produzia um prazer pela identificação, possível caso fosse permitida uma leitura mais livre, sem tanto controle e autocontrole (lembrando que a leitura do aluno já é, de antemão, condicionada pelos protocolos escolares de ensino do texto adquiridos ao longo dos anos). Esses possíveis efeitos da literatura, tomo-os de Aristóteles, em Poética 1995): prazer pela imitação e prazer pela execução, binômio que fez trajetória até nossos dias, e que Hans Robert Jauss (1994), por exemplo, traduz como fruição e conhecimento; Roland Barthes (1993), nos dois tipos de prazer, “jouissance” (gozo, fruição) e "plaisir" (o prazer mais imediato); e Umberto Eco vê manifestado no leitor vítima e no leitor crítico (1989). Ou seja, excluía-se dessa abordagem de A hora da estrela a possibilidade de a obra interagir com o leitor, a de atuar esteticamente (ISER, 1996) e produzir efeitos - de natureza sensorial, emocional, psíquica - no leitor. A individualização da leitura, a apreensão subjetiva do leitor, as emoções provocadas pelo texto, as relações que o leitor podia perceber com seu mundo, tudo isso era proibido em prol de uma leitura analítica que se pretendia distanciada, mas que não era uma coisa nem outra, já que não havia instrumentos para tal. O sujeito aí não estava nem se sentia concernido.

\section{Um projeto na escola que inclui o leitor de $A$ hora da estrela}

$\mathrm{Na}$ segunda resposta dos alunos a $A$ hora da estrela, e que se encontra descrita e comentada no texto publicado na revista Graphos (SOARES, REZENDE, 2019), a comiseração pela morte de Macabéa foi resultado de um projeto de leitura desse romance em uma turma de $1^{\text {o }}$ ano de Ensino Médio, em 2014, pela professora (e agora doutoranda), Sarah Vervloet Soares. O artigo resgata as etapas do projeto - a leitura do texto pelos alunos, a mediação de leitura pelo professor, a interação com a biblioteca escolar, atividades extraverbais, a produção do portfólio de leitura - cujo objetivo era "aproximar o aluno da prática da leitura", no caso, a de leitura literária.

Tendo desenvolvido o trabalho dentro do programa da disciplina de Língua Portuguesa e necessitando de um produto para avaliação, a professora optou pela elaboração em grupo de 
um portfólio ${ }^{4}$ que desse conta de todas as atividades realizadas durante a trajetória do projeto visita à exposição; leitura coletiva do conto "O primeiro beijo"; discussão de trechos da entrevista concedida por Clarice à TV Cultura, em $1977^{5}$ (disponível no YouTube); frases de Clarice que se tornaram conhecidas nas redes sociais; leitura em sala e em outros espaços da escola; características da protagonista; apresentação de músicas e trechos do filme $A$ hora da estrela de Suzana Amaral, de 1985, com discussão ao final. Além da descrição e do comentário dessas etapas, os alunos também deixaram registrados no portfólio suas ideias, sentimentos e emoções, gerados ao longo do trabalho ("Macabéa morre, sentimos pena de macabéa, sim, o nome está em letra minúscula pois tal nome não pode ser dito como próprio”).

Pode-se ver que, neste trabalho realizado por Sarah em sala de aula, houve um importante deslizamento de foco que significou também uma mudança teórica e metodológica: o foco se deslocou para a perspectiva da leitura, portanto, levando em conta o leitor. Essa perspectiva didática - à parte a leitura efetivamente realizada, compartilhada e debatida - considerou os diversos elementos de recepção da obra: a entrevista com a escritora, frases de Clarice nas redes sociais, o filme de Suzana Amaral. Quer dizer, levou em conta o leitor presente, naquele contexto, e levou em conta outros leitores que a leram, comentaram, transpuseram, desde a publicação do livro e não apenas os críticos literários. Em relação a esse percurso do projeto, trago um comentário que me pareceu bonito e muito apropriado, escrito por uma doutoranda do nosso grupo de pesquisa "Linguagens na Educação", após ter lido o artigo que assinei junto com Sarah para a revista Graphos:

Penso que o cinema (e a televisão, e, posteriormente, as mídias digitais) tem aqui um
papel excepcional. A entrevista da Clarice bem como o filme da Suzana Amaral fazem
uma diferença enorme em termos do trabalho de aproximação ao romance: uma
escritora de carne e osso (e não uma abstração de alguém que existiu e só é acessível
via uma biografia contada por outro sujeito também abstrato) que manifesta seu
sofrimento diante da morte ("agora estou morta”, diz ela) tornando viável a
aproximação com o leitor que sofre e se compadece com a morte da figura frágil de
Macabéa. Ofilme que realiza em imagens os símbolos que a leitura juvenil não pode,
sem esforço, descobrir (o cachorro-quente, a coca-cola que sujam o texto mal
datilografado, o creme branco que hidrata a pele, mas que desperta o desejo
inconsciente de comê-lo e talvez hidrataro interior ressequido da retirante, o homem
loiro que dirige a Mercedes Benz, a estrela que não é de Hollywood, mas do
automóvel que a atropela etc.) E a autora que se diz "morta" como todo fim de
trabalho nos coloca (morta de cansaço, morta da vida que não existe mais em
romance etc.) e que também é símbolo da morte do autor, anunciada pelos estudos
franceses (Barthes, por exemplo, e mais tarde Foucault), mas que não é vítima como
Macabéa porque tem potência criativa... Tudo isso que seria impossível há 30 anos

\footnotetext{
${ }^{4}$ Era também observada uma participação individual dentro do portfólio: havia uma assinatura de cada um quando determinada contribuição era autoral.

${ }^{5}$ Entrevista Completa com Clarice Lispector, concedida ao jornalista Júlio Lerner em 1977. Disponível em: https://www.youtube.com/watch?v=nhnhthPmL7s. Acesso 26/09/2020.
} 
quando não tínhamos recursos técnicos para mostrar o filme e nem a entrevista, $e$ quando ainda a televisão e as mídias eram malvistas. (Maria Celeste de Souza).

Ao abrir espaço no projeto escolar para a leitura subjetiva, com seu potencial catártico, a professora Sarah possibilitou, dentre outras aproximações pessoais dos alunos com a obra, a identificação com a personagem e, dessa forma, estimulou a implicação do jovem leitor escolar nas demais formas de apropriação da obra. Assim, a leitura subjetiva, tornou possível também apreender o contexto de produção, a relação com outras obras da autora e a contemporânea mediante outras linguagens (música e cinema) ${ }^{6}$.

A compaixão, essa piedade que o leitor manifesta em relação à personagem, é, segundo Annie Rouxel (2013), fundamental para o trabalho escolar, e não um obstáculo para a interpretação (esta, tradicionalmente objetivo último do ensino de literatura), como está suposto no trabalho didático que comentamos antes, o qual toma como ponto de partida o distanciamento crítico. É lugar-comum ouvir que o objetivo da escola é formar o leitor e “despertar o amor pela literatura". Ora, nada disso acontece se não houver envolvimento com o texto, de modo a possibilitar escolhas, identificações com estilos, autores, gêneros. O distanciamento crítico só é possível ao construir uma determinada biblioteca interior, um certo repertório que permita estabelecer comparações, operar seleções e, em última instância, desenvolver critérios críticos.

\section{A implicação do leitor nas atividades interpretativas: a leitura literária}

A partir de duas noções, utilizar e interpretar, formuladas por Umberto Eco $^{7}$ - em que a primeira pertence à esfera pessoal e a uma signficação para si; a segunda, à esfera social e a uma interpretação mais consensual e, assim, própria da escola -, Annie Rouxel propõe (em $2004^{8}$ ) a implicação de ambas as noções enquanto legítimas atividades do leitor na prática de ensino:

A interpretação visa, em verdade, a um consenso sobre um significado. Por sua vez, a utilização remete a uma experiência pessoal, que pode ser igualmente compartilhada

\footnotetext{
${ }^{6}$ Segundo os autores franceses Jean Verrier e Annie Rouxel, essas apropriações multissemióticas são meios de popularizar as obras clássicas e as aproximar do jovem leitor contemporâneo. Desses dois autores, são vários os artigos que remetem a essas visadas e se encontram na excelente revista dedicada ao ensino da língua, para a qual escreveram muitos artigos, Le Français d'aujourd'hui, em cuja apresentação se lê: "uma ferramenta de reflexão e de atualização dos conhecimentos em didática do francês, e mais precisamente sobre o ensino da língua e dos discursos, de um autor ou de uma abordagem literária e de abordagens pedagógicas inovadoras". Disponível em: $<$ http://www.afef.org/le-francais-aujourdhui-presentation $>$. Acessado em 20/05/2020.

7 A obra de Umberto Eco a que Annie Rouxel se refere é Seis passeios pelos bosques da ficção (Cia. Das Letras, 1994).

8 O livro, traduzido em 2013 por nós (integrantes do grupo de pesquisa Linguagens na Educação), Leitura subjetiva e ensino de literatura, originou-se do Colóquio "Sujets lecteurs et enseignement de la littérature", realizado em janeiro de 2004, na Université Rennes 2 e UFM de Bretagne, na França.
} 
...). A experiência conjunta da interpretação do texto e sua utilização por um leitor põe em tensão duas formas de se relacionar com o texto e com o outro e confere intensidade e sentido à atividade leitora. (ROUXEL, 2013, p.162) .

Trata-se de uma revisão teórico-metodológica importante da literatura no âmbito do ensino que tem se disseminado como uma perspectiva didática coerente diante da falência da leitura literária na escola.

A utilização do texto é antes de tudo sinal de apropriação do texto pelo leitor e fonte de seu prazer. É constitutiva da experiência do leitor. Ajuda a moldar "o texto do leitor", lugar de encontro entre os sinais do texto e a trama de uma existência. Esse texto do leitor está na origem de toda abordagem interpretativa. Por mais paradoxal que possa parecer, afigura-se urgente reensinar aos alunos a utilizar o texto para si mesmos, para sonhar, para reencontrar o gosto pela leitura. (ROUXEL, 2013, p. 164).

Tal apreensão teórico-metodológica de leitura literária acredito ser hoje disseminada entre professores que, de algum modo, estão atentos às pesquisas e à produção acadêmica - docentes dos cursos de licenciatura, pós-graduandos na interface língua/literatura/educação, sobretudo os professores do PROFLETRAS, docentes mobilizados como supervisores do PIBID, no programa de Residência Pedagógica etc. - profissionais e estudantes que se apresentam em eventos da área ou os acompanham seja presencialmente ou nas redes sociais, professores que participam de programa de formação de professores em parceria com as universidades (PIBID, Residência Pedagógica etc.). Infelizmente, das centenas e até milhares de relatórios de estágio entregues pelos meus alunos da FEUSP nestes últimos vinte anos, colho, no mais das vezes, informações sobre o ensino de literatura na escola básica que revelam uma concepção e uma prática bem semelhantes àquela primeiramente descrita, que eu mesma professei e pratiquei há cerca de trinta anos e que raramente rendem mais do que dispersão e desinteresse entre os alunos.

Não que as teorias sobre a recepção e o protagonismo do leitor não estivessem já em circulação ${ }^{9}$. Estavam, mas não possuíam ainda uma amplitude capaz de interferir nas práticas escolares. Em fins da década de 80, Eliane Yunes e Glória Pondé dão destaque, em livro dedicado à leitura da literatura infantil, à importância da instância do leitor no interior da revisão dos conceitos no âmbito cultural, em decorrência da alteração das relações entre produtor e consumidor de cultura:

(...) se antes a preocupação ficava centrada no texto, relegando-se o leitor para um plano secundário, hoje isso não é mais concebível. O texto só ganha vida se conseguir circular; para isso, tem que partilhar o complicado circuito que envolve o livro e chegar ao leitor. Contudo o fato de o livro atingir o consumidor ainda não resolve

\footnotetext{
${ }^{9}$ Por força do propósito deste artigo, aqui deixo de citar teorias sobre o texto literário, em especial o estruturalismo, que, naquele momento, também habitavam os livros didáticos. Em relação a esse assunto, mais uma vez, cito o mestrado de Carolina Yokota de Oliveira (pode ser consultado no Banco de Teses da USP).
} 
totalmente a questão da leitura, pois esse percurso pressupõe uma outra face: a da interpretação, ou seja, da recepção do texto pelo leitor. (YUNES, PONDÉ, 1989, p.7)

Percebem-se, nesse trecho, ecos de duas vertentes teóricas ${ }^{10}$ que, ao longo dos anos, foram se configurando no Brasil e se tornaram caras e concomitantes às questões de didática da literatura, encontrando-se, hoje, no centro das discussões acadêmicas sobre ensino de literatura: a leitura literária e a estética da recepção. Esta última ganhou ainda mais visibilidade na área de ensino a partir de 1989, com a publicação do livro de Regina Zilberman, Estética da recepção e história da literatura, em que sintetizava, comentando-o, o importante texto de Hans Robert Jauss, de 1967 - mais tarde publicado pela Ática (JAUSS, 1994) -, que protagonizava a crítica contra uma visão, segundo ele, ultrapassada de história da literatura, que não considerava a recepção dos leitores como instância da literatura ${ }^{11}$.

A Estética da recepção, como proposta metodológica, coleta as perguntas colocadas
às obras ao longo do tempo; o resultado é uma história da literatura que verifica, não
a sequência de autores e suas criações cristalizadas num momento passado, mas, sim,
como se deu e vem ocorrendo a comunicação desses produtos de cunho artístico com
o público, representado especialmente pelos seus segmentos mais avançados, a saber:
a crítica e o ensino. (ZILBERMAN, 1999).

A leitura literária, por sua vez, prioritariamente pensada para o trabalho na escola, é uma noção (conceito?) complexa, como afirma Munita (2017), genericamente identificada como perspectiva que coloca o foco na leitura, portanto, naquele que lê, o sujeito leitor, e não apenas no texto enquanto objeto de estudo. E acrescenta:

\begin{abstract}
Se se trata de formar leitores literários que se sintam implicados na leitura e que, além disso, possam acionar formas variadas de compreensão e fruição dos textos, trabalhar na aquisição e no domínio progressivo dessa forma de leitura parece ser a melhor contribuição que a escola pode fazer na formação do leitor das novas gerações. (MUNITA, 2017, p. 385, tradução minha) ${ }^{12}$.
\end{abstract}

Trata-se de um importante deslizamento de foco e crucial para a escola, que há muito é acusada de afastar os alunos da literatura, por ter substituído a leitura da obra por simulacros (OSAKABE, FREDERICO, 2004), ou porque faz mal o trabalho de mediação.

\footnotetext{
${ }^{10}$ As referências às novas teorias nesse livro de Yunes e Pondé ainda não se encontram explicitadas no texto, embora algumas já possam ser situadas no entorno da questão.

${ }^{11}$ Regina Zilberman (1999), no artigo “A Estética da Recepção e o acolhimento brasileiro”, historiciza a recepção das ideias de Jauss e Wolfgang Iser no Brasil no rastro da coletânea organizada por Luiz Costa Lima, em 1979, A literatura e o leitor. Embora eu mesma não tenha pesquisado maiormente a questão, arrisco-me a dizer que foi mesmo o livro de divulgação da Estética da Recepção, escrito por Zilberman em 1989, que mais influiu na popularização das ideias de Jauss no âmbito do ensino, enquanto a coletânea de Costa Lima parece ter incidido mais sobre os estudos literários.

${ }^{12}$ No original: "Pues si de lo que se trata es de formar lectores literarios que se sientan implicados en la lectura, y que además puedan ponder em juego formas variadas de comprensión y fruición sobre los textos, trabajar en la adquisición y el progresivo dominio de esta forma de lectura parece ser el mejor aporte que pueda hacer la escuela en la formación lectora de las nuevas generaciones."
} 
Segundo Brigitte Louichon, a noção ${ }^{13}$ de leitura literária é definida por alguns autores como sinônimo de leitura dos textos literários na escola, remetendo a competências específicas que a escola deve construir, e se o leitor ocupa um papel central significa que "a atividade na qual está envolvido é maciçamente designada como pertencendo à interpretação"14 (LOUICHON, 2011). Ambos, Munita e Louichon, se detêm na força que a perspectiva da leitura literária tem adquirido nestas duas décadas do século XXI e comungam no que diz respeito à importância da configuração e consolidação de um campo específico, a didática da literatura.

\section{Os desafios da leitura literária}

Como acompanhar essa formação do leitor a partir da leitura literária? Como levar a cabo a leitura de textos longos na escola, romances, por exemplo? Desafios enormes ${ }^{15}$. Por exemplo, no trabalho desenvolvido por Sarah Vervloet Soares na sua turma de ensino médio, o portfólio foi não só o procedimento de coleta de dados para avaliar a leitura dos alunos - concebendo essa leitura no horizonte da implicação de que fala Rouxel -, isto é, o portfólio abria tanto para manifestações individuais por escrito da utilização para si do romance como para aspectos de interpretação. O portfólio foi um instrumento utilizado por Sarah, mas também há outros ${ }^{16}$; um dos mais difundidos atualmente é o diário de leitura, que se combina na sala de aula com o debate coletivo, quando as impressões individuais são confrontadas com a dos outros colegas leitores, e que têm sido sinalizados em dissertações e teses acadêmicas (dentre outros, SILVA, 2018; SOUZA e SOUZA, 2019), dessa forma, sendo possível que as experiências individuais se alimentem das outras experiências e possam constituir comunidades de leitores.

De todo modo, como lembra Munita, é necessário que continuemos com as pesquisas de campo nas escolas para observar e analisar as práticas reais de ensino e de aprendizagem para "caminhar para uma compreensão mais justa e profunda dos diversos fatores que incidem na formação escolar do leitor literário" (MUNITA, 2017, p. 390, tradução minha) ${ }^{17}$.

\footnotetext{
${ }^{13}$ Brigitte Louichon (2011) sinaliza para a apreensão da expressão entre os especialistas da área: disse que tem oscilado de noção a pré-conceito e conceito, ainda que não nessa ordem.

${ }^{14} \mathrm{De}$ fait, si le lecteur est central, l'activité dans laquelle il est engagé est massivement désignée comme relevant de l'interprétation.

${ }^{15}$ Nesse sentido, é muito interessante o modelo proposto por Manon Hébert, professora do Departamento de Didática da Universidade de Montréal, para acompanhar alunos de 9 a 15 anos durante a leitura dos romances na sala de aula. A descrição da proposta e da experiência realizada se encontra no livro Lire et aprécier les romans en classe. Enseignement explicite, journaux et cercles de lecture [Ler e apreciar romances na sala de aula. Ensino explícito, diários e círculos de leitura].

${ }^{16}$ Um outro projeto de leitura de $A$ hora da estrela que também trouxe resultados muito estimulantes para a pesquisa e para a prática escolar foi desenvolvido em uma turma de Ensino Fundamental I e encontra-se descrito na dissertação de Ana Carolina Morais, do PROFLETRAS-USP, sob minha orientação.

${ }^{17}$ No original: "Avanzar hacia una comprensión más ajustada y profunda sobre los diversos factores que inciden en la formación escolar del lector literario".
} 


\section{Quando a recepção da literatura se encontra com os estudos culturais}

Extrapolando a especificidade do campo da didática ou do ensino de literatura e pensando nesses novos paradigmas de final do século passado (visíveis nos Parâmetros Curriculares Nacionais de meados de 1990), faço aqui uma breve tentativa de interconexão de alguns elementos do contexto que, decerto, estão implicados nessa mudança.

Como disse João Alexandre Barbosa (1994) - em um ensaio despretensioso sobre ensino de literatura de que gosto bastante -, "literatura nunca é só literatura: é História, Psicologia, Sociologia...”. A Estética da Recepção e suas filiações - como a teoria do efeito estético de Iser e seu grupo do Reader-Response Theory nos Estados Unidos (ISER, 1989), os estudos franceses relacionados ao sujeito leitor e à leitura literária - se pensadas para a escola, expandem-se em direção a um repertório literário muito mais diverso, para além dos textos clássicos que a escola está acostumada a utilizar.

As pesquisas sobre a recepção renderam estudos que abordam práticas de leitura de grupos mais variados, sem os juízos de valor que tradicionalmente costumam desmerecer essas práticas. São consideradas, no interior dessas novas abordagens, manifestações legítimas, uma vez que representam apropriações simbólicas caras a esses grupos. Como exemplo, cito aqui dois estudos de tema semelhante - sobre romances populares dirigidos ao público feminino -, o de Janice Radway, Reading the romance/women, patriarchy and popular litterature, de 1984, e a pesquisa de mestrado mais recente, defendida em 2012, de Patrícia Aparecida do Amparo, "Sonhando acordada: um estudo sobre as práticas de leitura da coleção de romances Clássicos Históricos". Sem a intenção de me deter sobre esses textos, trago-os apenas como exemplo de uma outra visão de cultura - e poderia citar muitos outros voltados para práticas sociais de leitura distantes de obras ditas universais - para remeter a estudos que não se referem apenas à literatura, mas têm, sobretudo, nela seu ponto de ancoragem e de desenvolvimento.

Segundo Cevasco (2003), os acontecimentos que dão visibilidade às mudanças na concepção de literatura têm lugar logo no pós-guerra, na Inglaterra, e paulatinamente se estendem por décadas e países, ganhando contornos variados, genericamente abrigados no guarda-chuva dos Estudos Culturais. Mas não era só de literatura que se tratava, esta se encontrava no bojo da revolucionária mudança do significado de "cultura": de sinônimo de distinção, dá lugar a uma dimensão antropológica na sua concepção - como modo de vida, como pluralidade, de culturas no plural -, contrapondo-se, na literatura, à noção de literatura universal, por exemplo, ocidental e branca. 
A manutenção exclusiva dessa literatura na escola, hoje, ironicamente, referenciada como "alta literatura", tem sido criticada por muitos setores da cultura e do mundo acadêmico ${ }^{18}$, embora ainda se mantenha como protagonista do campo intelectual e se mantenha nas práticas escolares, principalmente no ensino médio, onde vigora, alimentada, em parte, pelos vestibulares e, em parte, pelos livros didáticos (até há pouco, infensos no mais das vezes às críticas feitas pelas teorias da recepção contemporâneas, começam a incluir com dificuldade algumas mudanças, pela necessidade de adaptação às orientações e editais dos documentos oficiais $)^{19}$.

Por outro lado, esse novo paradigma de cultura tem fortemente se entranhado nas práticas sociais brasileiras e tem pressionado por mudanças na escola, provindos de setores em luta pela inclusão, democracia e igualdades de direitos, mediante movimentos sociais como os de gênero, raça, culturas populares, setores que têm lutado para se ver representados e que, como se disse, encontram eco em estudos acadêmicos e em currículos do ensino superior, bem como em leis e documentos oficiais federais, estaduais e municipais. Um dos resultados mais evidentes e poderosos dessa parceria entre lutas sociais, produção cultural e produção acadêmica, foram as leis 10.639/03 e o ensino da história e cultura afro-brasileira e africana e, posteriormente, a Lei $11.645 / 08^{20}$, que colocaram a cultura afro e a cultura indígena como obrigatórias no currículo do ensino básico. Além dessas, incluídas por força de lei, a BNCC - Base Nacional Comum Curricular - dispõe como itens para a construção de competências e habilidades na parte de Língua Portuguesa a mobilização também das culturas juvenis, a partir das quais entram formas contemporâneas de produção artística, bem como as culturas digitais e as chamadas práticas de multiletramento impulsionadas pela web.

Ainda que haja resistências advindas de diferentes grupos e espetacularizadas pela mídia, essas culturas avançam e interferem tanto nos currículos do ensino superior (PÉCORA, 2015) quanto naqueles do ensino básico, estes impulsionados também pela constatação da evidência de que não só o discurso sobre a escola mudou, como mudaram os alunos, imersos agora na

\footnotetext{
${ }^{18}$ Alcir Pécora, em artigo de 2015, "A musa falida: a perda da centralidade da literatura no mundo globalizado", comenta a mudança nos currículos das universidades, a partir da força emergente dos estudos culturais de procedência norte-americana da década de 1990.

19 No Brasil, o momento de maior visibilidade dessa polêmica entre visões contrapostas de literatura provavelmente tenha sido em 1995, quando Harold Bloom publicou o seu Cânone ocidental. O jornal Folha de S. Paulo publicou em agosto de 1995, no Caderno Mais, artigos de Arthur Nestrovsky, Bloom contra-ataca (06/08/1995) e de João Almino, A guerra do "Cânone Ocidental" (13/08/1995), cujos títulos já explicitam a polêmica que se seguiu.

${ }^{20}$ Lei ${ }^{\circ} 10.639$, de 9 de janeiro de 2003. http://www.planalto.gov.br/ccivil 03/leis/2003/110.639.htm; Lei No 11.645, de 10 março de 2008. http://www.planalto.gov.br/ccivil_03/Ato2007-2010/2008/Lei/L11645.htm Acesso em 26/09/2020.
} 
cultura digital, que lhes confere uma intercomunicação jamais havida antes, o que significa empoderamento em face da cultura escolar, posicionamento e confronto ideológico, muitas vezes. Por isso, é importante ouvi-los também.

Portanto, a essas questões que incluem os multis - multiculturalismo, multidisciplinaridade, multiletramentos -, se contrapõe no interior da cultura acadêmica a questão sobre o panteão da literatura, a literatura culta, adulta, ocidental e "branca", onde se depositam os grandes clássicos que compõem os estudos escolares. São e continuarão sendo referências de grande literatura, e nós, professores, queremos que os alunos cheguem também a eles. Levar em conta o leitor, como quer a estética da recepção, e se abrir para diferentes identidades, como querem os estudos culturais, também impõe lembrar que, assim como o cânone é móvel, também as identidades o são, portanto, o fato de a escola manter o seu próprio e tradicional repertório de leitura não é em absoluto negativo, mas não pode ser só ele.

\section{Referências}

AMPARO, Patrícia Aparecida do. Sonhando acordada: um estudo sobre as práticas de leitura da coleção de romances Clássicos Históricos. Dissertação de Mestrado. FEUSP, São Paulo, 2012.

ARISTOTELE. Poetica. Introduzione e note di Diego Lanza. Texto greco a fronte. Milano:Biblioteca Universale Rizzoli, 1995.

BARBOSA, João Alexandre. Literatura nunca é apenas literatura. Depoimento apresentado no Seminário Linguagem e Linguagens: a fala, a escrita, a imagem. Série Idéias n.17. São Paulo: FDE, 1994. Centro de Referência Mario Covas.

BARTHES, Roland. O prazer do texto. Trad. J. Guinzburg. São Paulo: Perspectiva, 1993.

BLOOM, Harold. O cânone ocidental. São Paulo: Objetiva, 1995.

CEVASCO, Maria Elisa. Dez lições sobre estudos culturais. São Paulo: Boitempo, 2003.

CHERVEL, André. História das disciplinas escolares: reflexões sobre um campo de pesquisa. Teoria \& Educação, n. 2, 1990, p. 177-229.

ECO, Umberto. O leitor, o prazer, o consumo. In: ECO, U. Sobre os espelhos e outros ensaios. Rio de Janeiro: Nova Fronteira, 1989.

FORSTER, Edward Morgan. Aspectos do romance. Trad. Sérgio Alcides. São Paulo: Globo, 1998.

HÉRBERT, Manon. Lire et aprécier les romans en classe. Enseignement explicite, journaux et cercles de lecture. Montréal (Québec, Canadá): Chenelière Education, 2019. 
ISER, Wolfgang. O ato de leitura. Uma teoria do efeito estético. V. 1 e 2/Tradução Johannes Kretschmer. São Paulo: Ed. 34, 1996.

ISER, Wolfgang. Prospecting. From reader response to literary anthropology. Baltimore and London: The John Hopkins University, 1989.

JAUSS, Hans Robert. A história da literatura como provocação à teoria literária. Trad. Sérgio Tellaroli. São Paulo: Ática, 1994.

LIMA, Luiz Costa (org.). A literatura e o leitor. Textos de estética da recepção. Rio de Janeiro: Paz e Terra, 1979.

LOUICHON, Brigitte. La lecture littéraire est-elle un concept didactique?. In Daunay, B., Reuter, Y.\& Schneuwly, B. (dir.). Les concepts et les méthodes en didactique du français. Namur: AIRDF-PUN, 2011, pp.195-216.

MORAIS, Ana Carolina de Oliveira, Uma experiência de leitura literária no Ensino Fundamental II: A hora da estrela, de Clarice Lispector. Diss. Mestr. Mestrado Profissional em Letras em Rede Nacional - PROFLETRAS. São Paulo: FFLCH-USP, 2018.

MUNITA, Filipe. La didáctica de la literatura: hacia la consolidación del campo. Educação e Pesquisa. São Paulo, v. 43, n. 2, p. 379-392, abr./jun., 2017.

OLIVEIRA, Carolina Yokota de. Um estudo sobre a concepção de literatura presente no discurso dos manuais didáticos (entre os anos de 1970 a 1990). Dissertação de Metrado. São Paulo: FEUSP, 2008.

OLIVEIRA, Gabriela Rodella de. O professor de Português e a literatura. São Paulo: Alameda, 2013.

OSAKABE, Haquira. OSAKABE, H.; FREDERICO, E. Y. Literatura. Orientações curriculares do ensino médio. Brasília: MEC/ SEB/ DPPEM, 2004.

PÉCORA, Alcir. A musa falida: a perda da centralidade da literatura na cultura globalizada. Biblos, n. 1, série 3, 2015, p. 203-235.

RADWAY, Janice. Reading the romance/women, patriarchy and popular litterature. Carolina (EUA): University of North Carolina Press, 1984.

ROUXEL, Annie. A tensão entre utilizar e interpretar na recepção de obras em sala de aula. In: ROUXEL, A., LANGLADE, G., REZENDE, N. Leitura subjetiva e ensino de literatura. São Paulo: Alameda, 2013.

SILVA, Eduarda Schneider da. Diários de leitura - um caminho para o incentivo à leitura subjetiva em turma de ensino fundamental da rede privada de Bagé/RS. Diss. Mestr. Universidade Federal do Pampa, Bagé, 2018.

SOARES, Sarah V., REZENDE, Neide. A leitura literária de A hora da estrela: um percurso de encontros e descobertas. Revista Graphos, vol. 21, $\mathrm{n}^{\circ}$ 1, 2019, UFPB/PPGL. 
SOUZA e SOUZA, Raquel C. Das (im)possibilidades de avaliar a leitura literária na escola: um estudo de caso. Revista Entreletras (Araguaína), v. 10, n. 2, jul/dez 2019 (ISSN 21793948 - online).

TODOROV, Tzvetan. Literatura em perigo. Rio de Janeiro: Difel, 2009.

YUNES, Eliana, PONDÉ, Glória. Leitura e leituras da literatura infantil. São Paulo: FTD, 1989.

ZILBERMAN, Regina. Estética da recepção e história da literatura. São Paulo: Ática, 1989. Col. Fundamentos.

ZILBERMAN. Regina. A Estética da Recepção e o acolhimento brasileiro. Moara. Revista do Programa de Pós-Graduação em Letras, UFPA, Belém, n. 12, p. 7-17, jul./dez. 1999.

Recebido em: 17/05/2020

Aceito para publicação em: 04/08/2020 